\title{
MODULAR SYNTHESIS OF OBJECTS OF SYSTEM OF MONITORING AND CONTROL OF TRANSPORTATION PROCESS PARTICIPANTS IN RAILWAY TRANSPORT SYSTEM OF MONGOLIA
}

\author{
Molchanova Elena \\ Federal State Budgetary Educational Institution "Irkutsk \\ State Transport University" \\ (FSBEI HE ISTU) \\ Irkutsk, the Russian Federation \\ mlchnv@irgups.ru
}

\author{
Battogtogtokh Batnysan \\ Federal State Budgetary Educational Institution "Irkutsk \\ State Transport University" \\ (FSBEI HE ISTU) \\ Irkutsk, the Russian Federation \\ nirunstan.mn@gmail.com
}

\begin{abstract}
The article describes the development of the structure of the objects of the monitoring and control system of enterprises of the railway complex. As the basis, within the framework of the development of the interaction of structural elements, lies the concept of the module (as a component). The article presents a general structure of interaction of the participants of the system of monitoring and controlling the movement of trains in Mongolia. The proposed approach reveals the integration to the system of monitoring and control of business processes of enterprises. The modular linking of individual objects of the system will help to provide essential assistance to management while constructing a reliable internal control system for the company's operations.
\end{abstract}

Keywords-control; railway transport; monitoring; system

\section{INTRODUCTION}

Throughout the world, railway is one of the main transport arteries. Railway transport ensures uninterrupted work of all economic sectors. The main purpose of the transport system of any country is to implement the passenger and cargo transportation of various types. This is the guarantee of economic development, the various systems of which are interconnected by rail, and is also a kind of products within the scope of an independent industry with a number of features.

As part of the railway traffic in Mongolia, the Ministry of Roads and Transport of Mongolia carries out the overall coordination.

The Ministry of Roads and Transport of Mongolia has established a structure that provides a system for monitoring the organization of train traffic, which includes the Unified Traffic Management Center and the Railway Transport Supervision Service. The Center has been operating since March 2013 and takes charge of the compliance with the unified schedule of train traffic and the collection of statistical information on the work of railway enterprises.
The main powers of the Center include the approval of a single train schedule, the organization and management of train traffic between railway infrastructures in order to ensure traffic safety; ensuring coordinated interaction in the management and organization of train traffic between railway infrastructures; making proposals and conclusions related to the management of train traffic and other

"Railway Transport Supervision Service" performs the functions of administrative control to ensure the safety of traffic, the quality of service, labor protection in railway transport through an annual inspection plan to ensure safety of railway transport; monitors the implementation of laws and regulations related to transportation activities, checks the compliance with security requirements and standards for railway transport, regardless of the type of ownership and location; restricts and temporary suspends the use of railway facilities in the event of conditions for accidents, wrecks and defects, investigates the causes, makes conclusions and takes measures for accidents, wrecks and defects in railway transport, followed by making proposals to the competent authorities for suspension, cancellation of license actions, certificates and other permits $[1,2,3]$.

With the existing system of informing the relevant structural units, i.e. in the form of systematic reports in electronic form between the Center, the Service and the relevant enterprises of the railway industry, the coordination remains rather weak and not always timely.

In order to ensure the effectiveness of the interaction between the parties involved in the transportation process, a unified automated monitoring system for monitoring and controlling the measures for the implementation of the traffic schedule, the collection and analysis of statistical information on the operation of railway enterprises, as well as the results of audits and operational inspections, including revisions [4]. The main objective of the study is to develop the structure of an automated system for monitoring and controlling the 
movement of trains in Mongolia and modular integration within the scope of the process participants $[5,6]$.

\section{DEVELOPMENT OF THE SYSTEM STRUCTURE}

The methodological basis of the research is based on the system approach, the theory of the operation of railway transport, the methodology of system modeling and the theory of decision-making.

To form such a monitoring and control system, it is necessary to identify and structure the information to be exchanged as a result of the interaction of the above structures, and, as a consequence, to develop the structure of the necessary data system [7].

The structure of the data system can include four subsystems - "Enterprise data", "Train traffic management", "Railway transport surveillance" and "Industry performance indicators", each of which may in turn include several modules (Figure 1).

The subsystem "Enterprise data" includes the following structural modules: "Infrastructure Owner" and "Carrier". Each element of the database contains the necessary background information in the form of the Company Charter, organizational and managerial structure, and contacts [10].

To register an enterprise in the database, one should select the appropriate type of enterprise (infrastructure owner or carrier) and, upon entering the subsystem, fill in its structural elements.

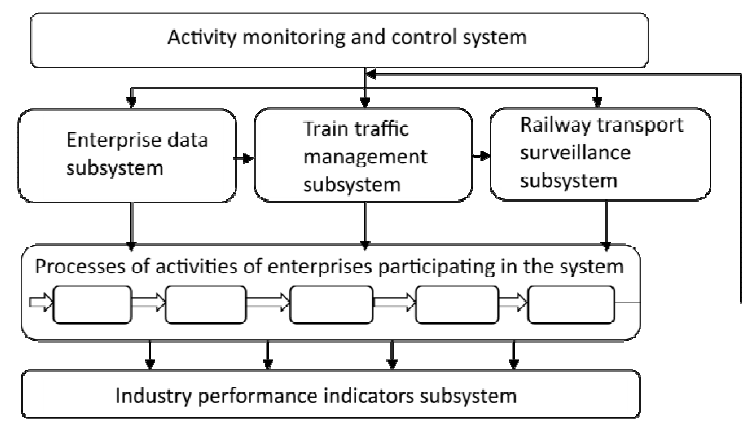

Fig. 1. A general structure of the monitoring system and control of the activities of railways in Mongolia

To manage the subsystem "Enterprise data", the following operations are provided: "Add an organization", after which there is a reference to the structure of the relevant sections and to the saving of the entered data.

After registration of the enterprise in the program network, a transfer to two other subsystems is provided on the basis on the selection of the appropriate command. The structure of the provided subsystems works only in relation to a particular enterprise in connection with its direct purpose.

Results on the performance of the functions of enterprises are presented in the form of data and information received in a certain period of time [11]. Therefore, it is important to select the period of the informing time (Figure 2).

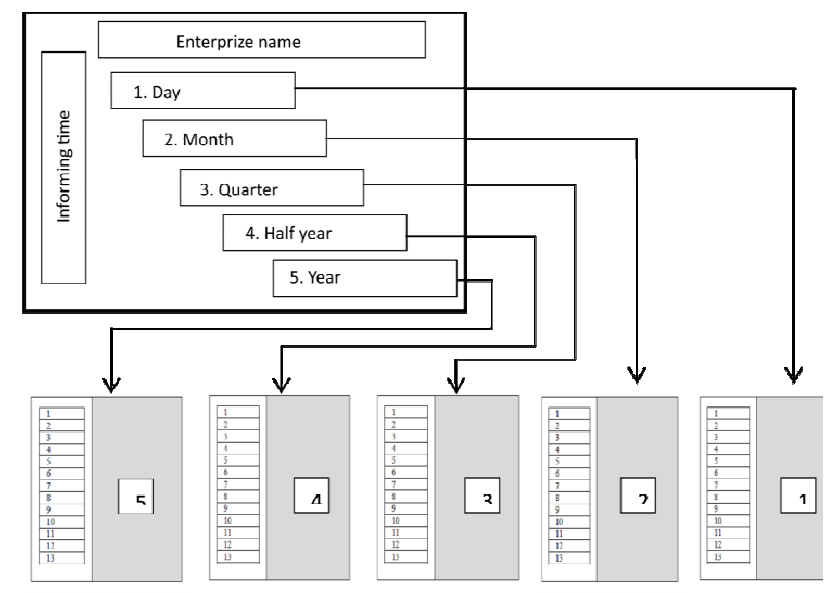

Fig. 2. A scheme of interrelation of the database element "Informing time" with the forms of reports

The main structural elements for a specific period of time in the system can be selected from the drop-down list that the subsystem will offer. For example, for the daily period, the following types of information are standard: a summary of the main indicators of the operational work of the railway enterprise, a summary of loading (by the cargo type), a summary of loading (by stations), a summary of unloading (by stations), a summary of the acceptance of trains, cars, a summary of delays of the schedule for the movement of trains; a report of a fleet of freight cars; a summary of the supply of freight cars to coal mines, and the remainder of coal at the CHP.

The structure and composition of elements associated with a specific period should be presented in a certain form, which has its own number, i.e. the number of the summary. So, when you press the "Summary form" key provided within the interface of the database element in question, a certain structure is formed to fill its individual elements (Figure 3).

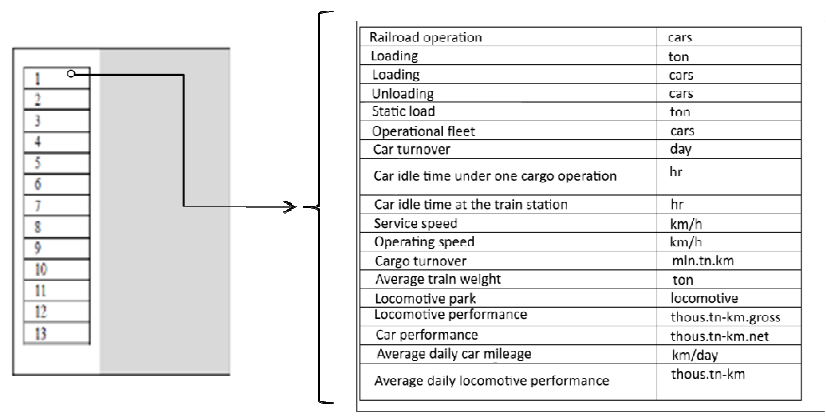

Fig. 3 A structure of the form of the daily summary of the main indicators of the operational work of the railway enterprise

To fill in the daily summary forms, open windows are used for the corresponding indicator, which is entered and automatically compared with the previously entered data at the beginning of the period: the planned indicator and the 
indicator for the previous day, resulting in a difference between the previous period and the reporting period, which is displayed with the sign "+" "Or" - ", which means an increase or decrease, respectively, relative to the corresponding reporting period.

The planned indicator is formed for a day automatically from the plan for the month and, accordingly, the annual plan.

As part of the analysis of this indicator, it is also possible to carry out an analysis of implementation in relation to the monthly plan. Calculation and graphical representation of the data for analysis are displayed automatically.

An example of monitoring results for the "Railroad operation" indicator is shown in Figure 4.

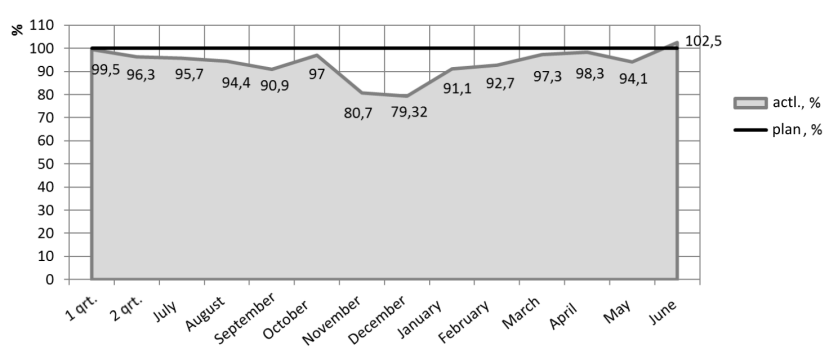

Fig. 4 Interpretation of monitoring results for the indicator" Railroad operation"

The request for information begins with the main form. If you select one of the items, the corresponding forms are displayed, in which the user is given the opportunity to view the list of corresponding tabs, select the required tab, and view the list of settings for this query. By the way, the list of settings is not available if you do not select a specific tab.

The information and structure of the proposed database is planned to be used in the development of modules of other subsystems: Train Traffic Management, Railway Transport Surveillance and Performance Indicators.

The subsystem "Train Traffic Management" includes the following structural modules: "Freight traffic", "Passenger traffic" and "Other indicators".

The "Freight traffic" module provides for the presence of the following structural elements of the database: average daily work; railroad operation (average per day); static load; dynamic load; calendar days; cargo shipping; turnover of goods; reception by stations; delivery by stations; working park; railroad operation (absolute); loading in wagons; loaded car accepted; loaded cars delivered; unloading in cars; turnover of the car; idle time of the car under one cargo operation; idle time of the car at a technical station; ton-km, gross; ton-km, net, etc.

The structure of the "Passenger traffic" module is represented by three elements of the database: passenger transportation, passenger turnover and the average distance of the passenger train; the "Other indicators" module includes the ton- $\mathrm{km}$, and the train schedule.
There are two modules, "Internal audit" and "External supervision", that are subordinated to "Railway transport surveillance" subsystem.

Internal audit at the enterprise is one of the ways to monitor the activities of individual management units to ensure compliance with relevant requirements or targets. As part of the activities of the Ulaanbaatar Railways, the internal audit is currently carried out within the scope of the traffic safety management system. At the same time, the requirements for labor protection and environmental safety are audited, and the internal and external requirements are audited for the activities of the enterprise.

The "internal audit" module consists of the following elements: planning, implementation, non-compliance control and risk management.

As part of the planning of internal audits, it is necessary to form an annual program of inspections, plans for their conduct, and, accordingly, it was necessary to provide for the availability of relevant elements in the module. As part of the implementation of internal audit plans and programs, as an objective evidence of their conduct and analysis of the results obtained, the system provides the blocks of reporting and productivity. The non-compliance control includes the tabs of corrective actions and corrections. The structure of the internal audit module is shown in Figure 5.

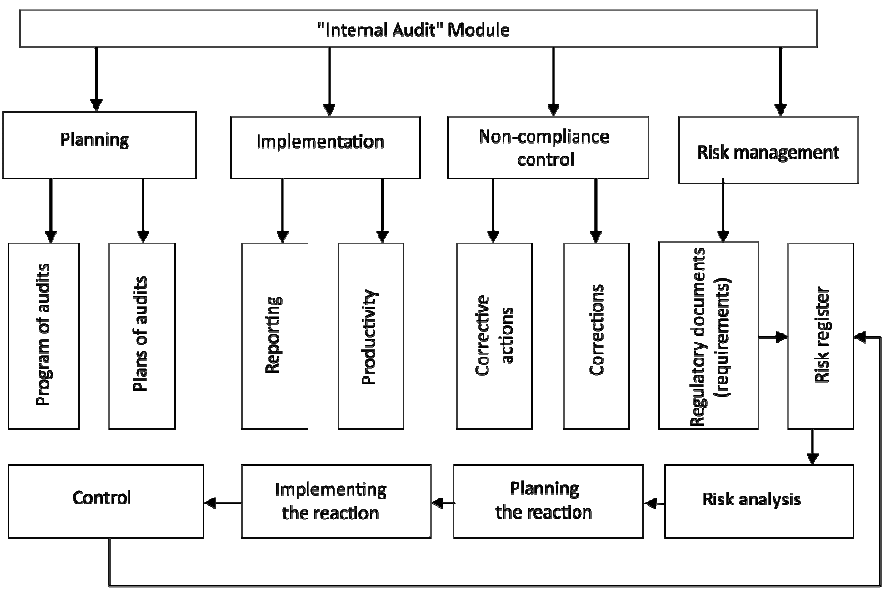

Fig. 5. A structure of the module "Internal audit"

The most relevant and complex in its configuration is the element of risk management - of conditions of uncertainty.

In accordance with GOST 33433-2015 Functional safety. Risk management in railway transport, the main task of risk management in railway transport is to achieve and maintain an acceptable level of risk while ensuring the functional safety of infrastructure and rolling stock facilities, including:

- Increasing the reliability and functional safety of technical equipment included in the infrastructure and rolling stock;

- reducing the likelihood of traffic accidents; 
- prevention or reduction of deaths and injuries of people;

- reduction of damage to property of the operators in the sphere of railway transport and other losses;

- prevention of unfavorable effects on the environment.

The relevance of research in the field of enterprise risk management is determined by the need to develop an integrated, comprehensive approach to risk management that is coordinated throughout the organization. The ability to effectively influence the risks makes it possible to successfully operate the enterprise, have financial stability, high competitiveness and stable profitability.

Based on the above, the purpose of inclusion in the monitoring and control system is the analysis of the risk management system in an enterprise operating in a market environment.

The goal of the research set forth predetermined the formulation and solution of a number of interrelated tasks for the formation of this module element:

1) to analyze risk management techniques at the enterprises of the railway complex in Russia;

2) to develop a common structure, corresponding to a complex of measures for risk management in enterprises.

The general scheme of risk management in railway transport includes the following operations:

- definition of the field of application;

- determination of the risk criterion;

- identification of risk;

- frequency analysis;

- analysis of consequences;

- determination of the level of risk;

- risk assessment;

- risk management;

- monitoring and revision of risk.

The risk management system includes the process of developing the risk target and risk capital investments; determining the probability of occurrence of the event; identifying the extent and magnitude of the risk; analyzing the environment; choosing a risk management strategy; choosing the risk reduction methods (risk management techniques) necessary for the strategy; deliberate risk treatment [13].

At present, the technology of integrated management of reliability, risks and resources at all stages of the life cycle (MRRR) has been introduced at railway transport enterprises. It is based on the use of a modern information platform to manage the technical content of the infrastructure of Russian railways. This technology provides increase of reliability and safety of functioning of objects of railway transportation on the basis of effective system of gathering data, data processing and management of risks and resources at stages of a life cycle.

The MRRR technology at the enterprises of the railway complex of Mongolia can be used only after the development of the least complex automated systems. Therefore, the development and application of the proposed monitoring and control system is currently relevant.

\section{CONCLUSIONS}

The reliability of the research is confirmed by the coordination of the projects of the user interface of the individual subsystems in the relevant enterprises involved in the transportation process. The analysis showed that the introduction of the developed monitoring and control technology provides the rationality of the decisions made, and measures designed to prevent inconsistencies are formulated in an orderly way. This will significantly improve the effectiveness and efficiency of the enterprises of the railway complex.

The proposed approaches were analyzed by the employees at the subdivisions of the Ulaanbaatar Railway.

The detailed model of the monitoring and control system for the activities of railroad enterprises can be applicable to all subdivisions in the Mongolian railway network and will improve the quality of ongoing production processes by increasing the operational efficiency of the management by increasing the information content of the relevant coordinating bodies that participate in the transportation process.

The use of the proposed approach will help to prevent inconsistencies in the implementation of planned and regulatory indicators in the work of the railway, reduce the time for providing and analyzing information, increase the efficiency of organizations involved in the transportation process [12], and improve the use of the control system for the activities of railroad enterprises in Mongolia.

\section{References}

[1] Munkhdelger Balzhir, "Hhe Perspective of Ulan-Bator railway", journal World of transport, Vol. 3, pp. 148-155, 2014.

[2] Balzhir Munkhdelger, "Prospective development of the Mongolian railway section," journal The transport business of Russia, Vol. 6, pp. 29-33, 2014.

[3] A. Baturin, Theory of optimal technical development choice railway network equipment, dis. doctors tekhn. sciences: 05.22.08, 2010.

[4] E. Molchanova, B. Battogtokh, "Integrative approach to the monitoring system of implementation of audits at the enterprises of the railway complexin Mongolia," journal Modern technologies. System analysis. Modeling»: scientific journal, Vol. 2. pp. 179-184, 2017.

[5] O.B. Ivanov, "The role of internal audit in ensuring the efficient functioning of a corporate risk management system," Audit reports, Vol. 10, pp. 61-72, 2014 
[6] O.B. Ivanov, "Organization of the internal control and audit system in the US railway transport," Journal "STAGE: Economic Theory, Analysis, Practice, Vol. 5, pp. 68-77, 2011.

[7] A.F. Egorov, P.G. Mikhailova, T.V. Savitskaya, "Intelligence system of forecasting and classification of hazards of chemical products and technogenic wastes for population safety increasing," Tsvetnye metally [Non-ferrous Metals, Vol.4. pp. 78-84, 2015.

[8] L.I. Papirovskaya, T.B. Efimova, M.V. Kondrashkin, "Unified corporate automated infrastructure management system," Journal of the Bulletin of transport of the Volga region, Vol. 3, pp.43-49, 2012.

[9] I.M Kokurin, V.L. Belozerov, "Complex of methods of monitoring trains and simulation of transportation processes," Journal "Izvestiya PGUPS": Intellectual technologies - transport. Vol. 2, pp. 27-31, 2012.

[10] B. Anudar, Improvement of the structure, organization of internal control and audit, Diploma work for a master's degree in business administration, 2013.

[11] JSC "Ulaanbaatar Railway", Internal Audit and Control Department, "Monitoring" (Evaluation of the implementation of the plan for the first half of 2016, services, departments, offices, centers of OAO "UBZhD"), 2016.

[12] M.I. Dli, O.V. Stoyanov, A.Y. Belozersky, "Model of presenting data of complex industrial projects in automated information systems of industrial enterprises," Software products and systems, Vol. 4 (112), pp. 210-218, 2015

[13] V.A. Eliseev, "Risk management in the practice of railway transport». Journal of Economic and Social and Humanitarian Research," Vol. 2 (14), pp. 18-25, 2017. 